\title{
El concepto de finalidad en psicología
}

\author{
Antoine Vergote \\ Universidad Católica de Lovaina \\ Lovaina, Bélgica
}

La idea de finalidad se revela omnipresente en psicología desde los mismos lazos naturales que existen entre la ciencia y la práctica que la configuran y expresan; y se impone en ella, indiscutiblemente, por el hecho de que el ser humano es un ser de proyectos intencionales. Tal idea se extiende, sin embargo, más allá de las intenciones conscientes. Comprender al ser humano implica también conocer lo que lo hace actuar con espontaneidad psicológica, que él no determina intencionalmente. En psicología será preciso, pues, distinguir al menos dos clases de finalidad y examinar la articulación entre ellas: la finalidad intencional y la que organiza la acción no conscientemente intencional, no deliberada, que podemos denominar teleonomía.

psicología / finalidad / teleonomía / automotivación

\section{The concept of finality in psychology}

The concept of finality is omnipresent in psychology. The natural relationship that exists between science and practice in psychology configures and expresses this concept. Finality imposes itself to psychology by the fact that humans are beings of intentional goals. Nevertheless, such idea extends itself beyond conscious intentions. To comprehend a human being implies to know also what makes her/him behave with psychological spontaneity which is not intentionally determined by her/him. In psychology it will be necessary to differentiate at least two types of finality and examine the relationship between them: the intentional finality, and the finality that organizes the non-consciously intentional, non-deliberate action which we shall call teleonomy.

psychology / finality / teleonomy / self-motivation

Traducción del francés por Luis Ramírez Aguirre, de "Finalité en psychologie" publicado en 1998 en Le Supplément 207, Revue d'éthique et de théologie morale, pp. 67-93.

Dirección del autor: Facultad de Psicología. Universidad Católica de Lovaina. Tiensestraat 102. B-3000 Lovaina, Bélgica. 
El tener que referirme a "la psicología" me pone siempre en un cierto apuro, pues se trata de una disciplina fragmentada. Como el demonio, ella es legión. Es un mundo en el que los continentes teóricos se derivan a partir de diversas fracturas. Su objeto mismo es tan complejo como el ser humano, pues, como he insistido en mi contribución al volumen Nature et culture (1993) todo en el ser humano es psicológico, aunque nada lo es exclusivamente. Lo psíquico se arraiga en el cuerpo biológico y neurológico; incorpora el lenguaje con sus potencialidades y realiza diversas mediaciones entre este cuerpo y la consciencia, y entre sí y el otro. La idea de finalidad, por su parte, también es omnipresente en la comprensión psicológica. Pero siendo ella ahí múltiple, será preciso diferenciar sus modalidades.

\section{SOBRE LA PSICOLOGÍA COMO TEORÍA Y COMO PRÁCTICA}

La psicología como ciencia conduce a prácticas que se hallan estrechamente asociadas a ella y que, por ese hecho, la integran en su sentido de disciplina. Así, tenemos la psicología clínica, la psicología organizacional, la psicología educativa, etc. Estas disciplinas unen ciencia y práctica. Distinguiendo claramente entre una y otra conviene reconocer su necesaria alianza. La práctica es un lugar importante en el que se hacen observaciones que sirven a la construcción de los conceptos teóricos y a la prueba de su verificación.
Las teorías, por su parte, guían la práctica; al menos deberían hacerlo.

Los mismos lazos naturales entre ciencia y práctica nos señalan que la finalidad es omnipresente en psicología. En efecto, si hay una práctica solidaria de las construcciones teóricas, es porque éstas nos aclaran los dinamismos y procesos presentes en el ser humano que la práctica psicológica tiene precisamente por tarea optimizar. La psicología organizacional apunta a mejorar la cooperación entre los miembros de la organización y lograr una más eficiente utilización de sus cualidades individuales; la psicología clínica práctica tiene por meta ayudar a emplear oportunamente las técnicas terapéuticas, adaptándolas a las vicisitudes de los casos particulares. En general, apoyándose ampliamente en finalidades que se hallan en el hombre por su naturaleza humana -naturaleza culturizada-, la práctica psicológica las promueve, corrigiendo su realización deficitaria. A su manera ella aplica el antiguo principio: medicus curat, natura sanat.

$\mathrm{Al}$ señalar que las prácticas psicológicas inscriben sus finalidades en las de los seres humanos del medio cultural en que se ejercen aquellas prácticas, recojo desde ya de la ciencia psicológica su magisterio sobre las finalidades de las actividades humanas. No querría sin embargo que la ciencia psicológica se limitara a la tarea de elaborar el inventario de las diferentes metas per- 
seguidas por los seres humanos de los diversos medios socioculturales. Sin precisar desde ahora lo que esto significa, adelanto la tesis de que la psicología explica e interpreta lo que ella observa. Ahora bien, toda explicación en ciencias humanas implica una toma de distancia crítica con respecto a los hechos observados. Si la tarea de la psicología no es la de determinar las finalidades de la existencia humana, al interpretar y explicar más o menos las que los individuos se dan, ella abre no obstante un espacio de libertad crítica en su existencia.

No es porque la práctica psicológica tenga por meta optimizar las actividades humanas, que la psicología como disciplina teórica y práctica tiene la competencia de prescribir al ser humano el sentido y finalidad de su existencia. Sin embargo, la finalidad general de la práctica psicológica ha podido engendrar una peligrosa ambigüedad a este respecto. Quisiera recordar brevemente cómo la tarea práctica de optimizar las actividades humanas ha podido volverse sobre la teoría y hacer de ésta una ideología que se integra a otras ideologías, haciendo perder así a la psicología su alma humana.

La psicología tiene por objeto una esfera particular del ser humano que no es ni la esfera de la razón lógica, ni la del cuerpo orgánico. Más bien, la de lo irracional penetrado de razón. Ahora bien, fue una época de gran racionalidad técnica la que vio nacer a la psico- logía. El cuidado del perfeccionamiento técnico en todo dominio impulsaba desde entonces a los responsables a estudiar los medios de mejorar el funcionamiento del ser humano, en tanto que él es también el ser psicológico. En este contexto de civilización, la ciencia psicológica pudo tomar direcciones opuestas. Por un lado, ella ilustró sobre los efectos negativos que recaen en las empresas humanas por el desconocimiento, incluso violación, de factores humano-psicológicos. Por otro lado, ella se vio confrontada a una civilización técnica que mostró la tendencia a recurrir a sus servicios con el fin de dominar los factores humanos reacios a sus proyectos. Al poner la ciencia al servicio de fines utilitarios, la sociedad manifiesta tendencia a desviar aún las concepciones teóricas de la psicología en el sentido de un determinismo psicológico. Las dictaduras marxistas y nazis, incluso, imponían la enseñanza de la teoría conductista del condicionamiento, y aplicaban ésta sistemáticamente en el adiestramiento ideológico; pero rechazaban la teoría y la práctica psicoanalíticas. Con menos violencia, grupos de creyentes integristas manifiestan las mismas preferencias y descréditos.

El espíritu utilitario de una sociedad y el prestigio acordado a las ciencias "duras" y vinculadas a las técnicas pueden pesar igualmente en la orientación dada a la elaboración teórica en psicología. El deseo de obtener elementos 
teóricos garantizados por un método riguroso, de preferencia experimental, lleva a algunos medios a reducir los factores psicológicos a los que son susceptibles de ser examinados por un método semejante. Evidentemente, no es por azar que son segmentos psicológicos los que se prestan allí para ser dominados y utilizados con fines técnicos. En virtud de la civilización que le ha dado nacimiento, la psicología se encuentra así tentada de imponer una suerte de filosofía positivista, práctica. El hecho de que numerosas facultades de psicología hayan reducido en extremo o simplemente eliminado de sus programas la formación filosófica, en particular la antropología filosófica, es con frecuencia el signo de la voluntad de los psicólogos de ejercer su hegemonía teórica sobre el ser humano.

Al reflexionar sobre la finalidad en psicología debemos tener cuidado con todo aquello, pues la ciencia psicológica, que toma por objeto la finalidad en el ser humano, está animada por una secreta finalidad: la del psicologismo. Uno lo encuentra en diferentes tipos de psicología: en el conductismo que, de metodología, se transforma en ideología; en los rebajamientos teóricos de las motivaciones por el pseudoconcepto tan difundido de necesidad; en las explicaciones freudianas de los símbolos religiosos y estéticos; en la psicología jungiana en general.

La idea filosófica tan ambigua de "naturaleza humana" ha favorecido la desviación psicologista, sea en un sentido materialista, sea en un sentido aparentemente espiritualista. La psicología, que es una hija tardía de la filosofía, ha tenido la tendencia a retomar esta idea y a menudo ha alimentado la ambición de sustituir su antropología científica a la aparentemente más intuitiva e imaginativa de la filosofía. Practicando la psicología de la religión he vivido esa experiencia. A menudo he debido batirme en dos frentes contra el psicologismo. Hay creyentes que exigen a la psicología que demuestre que el ser humano es por naturaleza religioso. Los incrédulos, por su parte, piensan muy a menudo que la psicología explica la religión al revelar sus fuentes y sus mecanismos psicológicos puramente naturales pero religiosamente desviados.

En lo que sigue, habré de considerar algunos conceptos teóricos importantes, destacando lo que ellos nos enseñan acerca de las finalidades en la realidad psíquica del ser humano.

\section{Primera clarificación conceptual}

La comprensión psicológica del hombre implica manifiestamente la idea de finalidad. A propósito del comportamiento de una persona se busca espontáneamente comprender las razones por las cuales ella actúa del modo como lo hace. Dar las razones por, equivale aquí a explicar la actividad por el fin perseguido. La pregunta del "por qué" que el niño plantea incesantemen- 
te corresponde a la del para qué, a vistas de qué. Los seres humanos extienden, incluso intuitivamente, la explicación por la finalidad a los movimientos y maneras de ser de los seres vivientes en general. Así, se dice por ejemplo que los estorninos o los pericos vuelan en masa caótica para desconcertar a la eventual ave de rapiña que arremete contra ellos. O que el camaleón toma el color del soporte sobre el que se apoya para esconderse. El ser humano considerará posteriormente que, lo que le permite al animal sobrevivir, es un beneficio; él hará de éste un fin perseguido en el proceso observado. A menudo se ha atribuido a Aristóteles este tipo de explicación finalista, habiéndose llegado a oponer este finalismo aristotélico a la explicación científico-causal introducida en el siglo XVII, y establecida sobre todo en el XVIII en base al modelo de la prueba experimental. La idea de finalidad sería opuesta a la razón científica por dos razones. En primer término, como el fin es por definición lo que aún no se ha realizado, éste sería necesariamente un factor que no pertenece a lo real observable. Aristóteles diría por su parte que la causa final es un principio exterior, en tanto que las causas materiales y formales son principios interiores. La causa eficiente es también un principio exterior, aunque ella precede y pertenece a lo real. Segunda crítica: la causalidad final implicaría una inversión del tiempo. Lo ubicado en el futuro determinaría lo que le es precedente. El problema de la finalidad es, pues, el problema de la relación entre lo posible y lo real, y el de la temporalidad. Los dos aspectos están ligados.

Me dedicaré primero al factor temporal. Para el orden temporal, la pregunta se plantea respecto del vínculo intrínseco del futuro con el pasado, y del vínculo de lo que es presente y cambia con el futuro. Es, en efecto, pensando el movimiento como devenir, luego, como no caótico sino como ordenado, que Aristóteles generalizó la idea de causa final. No obstante, él no la interpretó como una intención de naturaleza psicológica dentro de la naturaleza, pues reservó la finalidad intencional, personal, a su tratado ético, y la finalidad englobante a su tratado de metafísica. Habría pues, para Aristóteles, diferentes tipos de finalidad: aquélla, que forma parte de la organización de la especie como especie; aquélla, ética, de la intención en las acciones humanas; y aquélla, metafísica, que regula los movimientos en el cosmos.

La crítica de la idea de causa final, que denuncia la inversión del tiempo, pierde su pertinencia en la comprensión psicológica. Cuando el escultor tiene una idea de la estatua que quiere hacer surgir del bloque de mármol, esa idea no es exterior al que actúa (la causa eficiente). Como dice Kant, el nexus finalis funciona ahí en los dos sentidos: del futuro al pasado y del pasado al futuro. La idea precede a la realización 
pero actúa en el actante que le da realidad efectiva.

La idea de finalidad se impone indiscutiblemente en psicología por el hecho de que el ser humano es un ser de proyectos intencionales. Esta idea se extiende, mientras tanto, más allá de sus intenciones conscientes. En efecto, hay psicología, porque el ser humano no es un cuerpo biológico revestido de una consciencia intencional. Numerosos comportamientos humanos manifiestan espontaneidad preconsciente $o$ no consciente. Comprender al ser humano implica también conocer lo que lo hace actuar con espontaneidad psicológica que él no determina intencionalmente. El ser humano llega pues a ser lo que él es, tanto por lo que lo hace actuar, como por lo que él hace intencionalmente. ¿Es que allí la oposición entre causa y finalidad no debe ser superada? Concebir la finalidad como el ghost in the machine bien parece no ser más que el efecto de una concepción simplista de la causalidad.

Será preciso pues distinguir en psicología al menos dos clases de finalidad y examinar la articulación entre ellas: la finalidad intencional y la que organiza la acción no conscientemente intencional, no deliberada. Propongo llamar $t e-$ leonomía a esta última finalidad, y retomar la definición que Monod ha dado de este término: teleonomía es la "actividad orientada, coherente y constructiva" (1970: 59). La ventaja de este término es que contiene la idea de regula- ridad, por tanto, de necesidad. La afirmación de esta necesidad en las acciones teleonómicas no es más que hipotética, como veremos. Ella permite, sin embargo, establecer lo que se puede denominar leyes que regulan los comportamientos. En cambio, en la medida en que la finalidad es conscientemente intencional es que escapa, precisamente, de las coacciones nómicas. En razón de la regularidad que rige los comportamientos teleonómicos, se puede también hablar de telecausalidad, pues finalidad y causalidad se imbrican allí la una en la otra. El término telecausalidad se presta entre tanto a malentendidos, y puede hacer reaparecer el espectro del ghost in the machine.

\section{Análisis de la acción}

El lenguaje ordinario, natural, en el que el ser humano expresa su actuar, contiene una red de términos remarcablemente articulados. Como Wittgenstein remarca en las Philosophische Untersuchungen (1969: 611-661), nosotros hablamos de modos muy diferentes, según se trate de fenómenos naturales o de nuestras acciones. En lo que concierne a los fenómenos naturales, hablamos en términos de movimiento o de acción en los cuales una fuerza actúa sobre algo que le es exterior. Se dice de un medicamento, que actúa sobre la fiebre; o del viento, que abre la ventana. Se construye así una secuencia de antecedente y consecuente. Pero de mi propia acción diré, por ejemplo, a 
aquéllos con quienes hablo: "un momento, voy a abrir la ventana para airear el ambiente porque comenzamos a sofocarnos". Yo, como sujeto actuante, estoy en la acción misma de ir hacia la ventana y abrirla. Hay unidad entre el sujeto actuante y la fuerza que actúa; esta unidad se da inmediatamente. Por ella la acción es intencional; dicho de otro modo, la intención es interior a la fuerza que actúa, determinando por eso su sentido. Aquí, como sucede a menudo, la palabra sentido tiene ambas significaciones: aquélla de la dirección del movimiento (ir hacia) y aquélla de la intención o de la finalidad (para abrir, para airear, para respirar bien). La intención que anima y orienta la acción determina la unidad de la secuencia, pues contiene anticipadamente el efecto. La acción se distingue así de la causalidad en el mundo físico donde la causa es exterior al efecto y donde el antecedente precede, sin más, a la consecuencia.

El ser humano asume también el mundo natural en sus acciones intencionales. De las cosas él hace herramientas, objetos-para, incluso herramientas para hacer otros objetos-para. El homo faber es una dimensión fundamental del ser humano. Y sin duda es este homo faber el que presenta el esquema mental que se halla en el origen de los conceptos de causalidad, según su articulación cuaternaria. En todo caso es en relación a él que Aristóteles pensó inicialmente los cuatro conceptos de causa.
La unidad de la intención, por tanto de la finalidad, con la acción es tan estrecha que se debe reconocer que la finalidad intencional tiene una fase pública y una fase privada, que ella se manifiesta y se oculta en la acción. Ésa es la parte de verdad de la idea formulada en el enunciado crítico (ghost in the machine). La ironía comienza al pensarse la acción en términos de una secuencia de causas: el espíritu pondría en movimiento al cuerpo que se mueve enseguida hacia la ventana y la abre. Se habla entonces de mentalismo y se rechaza la idea de que el espíritu pueda causar un efecto sobre el cuerpo y sobre el mundo material. El problema así planteado no es sino un artefacto creado por un lenguaje tomado del orden de la causalidad física, que se tiene a priori como más verdadero que el lenguaje natural de la acción. La crítica le atribuye al lenguaje de la finalidad una suerte de platonismo que se halla ampliamente diseminado en muchas discusiones epistemológicas.

Reflexionemos sobre los comportamientos naturales del animal. El animal en la vida natural nos instruye mejor que aquel otro que el conductista encierra en una caja con el fin de forzarlo a ilustrar, por un comportamiento aprendido y restringido, la teoría del condicionamiento. La finalidad organiza con toda evidencia el comportamiento animal. Esta finalidad puede incluso ser sorprendentemente "inteligente". En un zoológico de Brasil he podido ver a 
una ardilla inteligente subir a un árbol con una nuez de coco y dejarla caer en repetidas ocasiones sobre una piedra gruesa hasta romperse. Esta ardilla no habría podido decir: "yo subo para... porque yo tengo sed". Ningún esfuerzo paciente le enseñaría aún los primeros elementos del lenguaje, es decir, no simplemente algunos signos, sino la estructura gramatical que articula y expresa la finalidad. Para realizar una acción final intencional, al contrario, es preciso disponer de inteligencia. La finalidad intencional es parte de la mente, y es por eso que la idea de finalidad en el mundo natural crea un problema. Pero, ¿por qué querría uno limitar la finalidad a la mente? En el animal la finalidad y luego la racionalidad, que regulan muchos de sus comportamientos, son biopsíquicas. Evidentemente, esta manera de caracterizarlas no es más que descriptiva. Pero el identificarlas así indica en qué sentido será preciso pensar la estructura y los procesos complejos que la palabra "biopsíquica" recubre. El problema es, de una parte, el del pasaje, en el individuo, del cuerpo viviente a la consciencia perceptiva y a la acción finalista - con finalidad- $y$, de otra parte, el de la formación por evolución y de la transmisión por herencia de la finalidad inherente a la psicobiología del animal. Parece difícil negar que el orden de las causas físicas haya producido el de la finalidad. ¿Puede uno pensar las causas cósmicas como cargadas de la información necesaria a esta evolución?
Volvamos a la acción humana. Ahí la finalidad es inherente a toda acción, como ya lo he afirmado, oponiéndome al dualismo de la intención y el movimiento. La consideración del comportamiento animal facilita esta concepción unitaria. Se puede pensar, en efecto, que en el ser humano una finalidad intencional puede incorporarse en la acción teleológica del viviente biopsíquico.

Recientes teorías neuronales concuerdan con esta concepción. Ellas le confieren realidad física a las observaciones de la etología y a la fenomenología de la naturaleza finalista de la acción humana. Según el neurólogo Pierre Karli: “... el organismo utiliza los instrumentos sensorio-motores -característicos de la especie a la que él pertenece- para explorar su medio de vida y para insertarse de manera activa en un entorno que le será propio..." (1995: 39-40). Aún más: en el feto se observa un “... pasaje de [la] motricidad espontánea pre-intencional a una motricidad intencionalmente interactiva con el mundo..." (1995: 42). De la observación clínica surge "... que existe también un sustrato nervioso de la curiosidad y de la iniciativa psicomotriz" (1995: 43). Karli propone desde ahí pensar en el funcionamiento neuronal que rige la acción según dos principios: el de la "causalidad ascendente", que va de lo elemental a la organización más compleja, y el de "la causalidad descendente" que organiza, valida y 
adapta (1995: 55-56). En la causalidad descendente, tal como la concibe Karli, la finalidad es el elemento estructurante. En este sentido, se podría hablar de una telecausalidad, sin por eso localizarla en un elemento particular, pues esto implicaría confundir, entre ellas, las causalidades ascendente y descendente. La trampa en esta materia estaría en querer representarse imaginariamente la causalidad descendente. Investigaciones recientes conducen a neurólogos a afirmar que el cerebro simula los movimientos muy complejos de las acciones y que desarrolla hipótesis estratégicas de éstas, teniendo en cuenta múltiples referentes, por ejemplo, el mantenimiento de la cabeza inmóvil y el cálculo de la relación distancia-elevación durante el salto... Haciendo esto, el cerebro aprovecha de códigos dinámicos, pues la memoria es dinámica, y el código no es aquél -cartesiano- de un lugar sobre un espacio, sino aquél del movimiento egocéntrico. $Y$ porque el movimiento es egocéntrico, él es también capaz de tomar referenciales alocéntricos y de simular acciones de desplazamiento.

Propongo aplicar el término de teleonomía a esta estructura teleológica de la acción. En efecto, la acción es una actividad orientada, coherente y constructiva. Estos tres términos son indisociables. La coherencia de sus múltiples componentes le viene de su orientación que es teleológica, en tanto ella se dirige a construir el medio del viviente. El medio, en verdad, no es una situación dada de antemano; es lo que la acción animal o humana construye. Y el actante de esta construcción es el cuerpo animado por el sistema neuronal, organismo que despliega sus actividades estratégicas.

La idea de finalidad se desprende, pues, del vínculo que se había podido pensar intrínseco a la consciencia. Incluso diría que es la estructura teleonómica biofísica la que hace posible la finalidad perseguida por el yo consciente. La etología, la psicología del comportamiento humano y la neurología de la acción nos obligan así a superar el dualismo que divide a los seres en cosas físicas y en cuerpos dotados de espíritu; dualismo que se reencontraría al interior del ser humano. El psiquismo es un ser intermediario en el que una finalidad teleonómica organiza el comportamiento. Me parece que estas observaciones nos liberan del cuadro en el cual, desde Kant, se ha pensado la teleología, refiriéndose a aquélla que organiza la "naturaleza", pero no a la que organiza la acción. La acción en eso no es comparable al árbol que produce sus partes y donde, inversamente, las partes producen al organismo viviente.

La fenomenología de la percepción también ha esclarecido, progresivamente, la finalidad como principio organizador del cuerpo psicológicamente animado. En su obra fundadora de 1900, Les recherches logiques, Husserl se opone a la concepción según la 
cual la percepción consistiría en formar imágenes (Bilder) de las cosas ${ }^{1}$. Para él, la percepción es una exploración dinámica del mundo; luego ella se halla animada por una finalidad. Husserl toma así posición contra el idealismo y el positivismo que no aprecian en su valor la finalidad que es un principio organizador del cuerpo perceptivo. Pero, al inicio él pareció ligar todavía la finalidad a aquella que plantea o que capta el yo consciente. Su obra Idées I (1913) corregirá luego esta ambigüedad, demostrando que el telos que rige la percepción no es un dato (un objeto) de percepción, sino que es, en ella, como la idea reguladora. Esta idea no implica la consciencia de esta idea. Con una expresión muy fuerte, a la que Merleau-Ponty tuvo particular afecto, Husserl denomina la operatividad teleológica de la percepción: fungierende Intentionalität. Antes de ser una intencionalidad reflexiva, consciente de ella misma, la finalidad opera en la vida natural del cuerpo desplegando las percepciones dinámicas. Esta vida natural del cuerpo representa la animalische Natur en el hombre, tal como se lee en la obra Idées II. Y Husserl sitúa ésta entre la naturaleza material y el mundo espiritual. Este último se respalda en la Leib de la animalische Natur y ahí se arraiga. En el mundo espiritual, el telos corporal de la percepción deviene en el

1 Véase el estudio de Bernet (1994: 121-186). ideal consciente del conocimiento de la cosa tal como ella es, este telos característico de la civilización occidental.

Heidegger y Merleau-Ponty han continuado la vía trazada por Husserl; ambos han efectuado la crítica del conocimiento como hecho de representaciones que componen un espejo de la naturaleza. Ellos elaboran la idea husserliana del telos que rige y organiza la percepción, y esclarecen la relación circular entre la acción, por un lado, y la percepción y el conocimiento, por el otro.

Si el cuerpo perceptivo es ya un dinamismo teleológico operante en la interpretación constructiva que es siempre la percepción, permanece la pregunta por saber cómo se puede pensar el cuerpo sin la unidad de un yo consciente. Neurocientíficos hablan de estrategias egocéntricas y alocéntricas del sistema neuronal. Pero, ¿cuál es aquí el ego? El mismo Husserl se enfrentó a este problema al que le consagró nuevos estudios después de 1930, los que conciernen a lo que él denominó la constitución pasiva. Esta cuestión se halla, igualmente, en el centro de la teoría psicoanalítica de Freud. Allí volveré.

\section{La psicología del desarrollo}

J. Piaget es el célebre teórico de una psicología del desarrollo rigurosamente finalista. Algunas palabras sobre ella bastarán, así lo espero, para presentar el principio teórico que la comanda. 
Piaget estudia al sujeto en interacción con su medio. Este sujeto, por estructuras de las que dispone desde su nacimiento, procede inicialmente a la asimilación de las propiedades de las cosas. A continuación, él experimenta la resistencia que oponen estas cosas a ser asimiladas por las estructuras disponibles, predonadas. El sujeto se halla así forzado a modificar sus estructuras y a acomodarse a los objetos con el fin de asimilar de ellos, de otro modo, y mejor, sus propiedades. Esta acomodación se hace por abstracción reflexiva: el sujeto adopta en un primer nivel formas que le permiten asimilar las propiedades de las cosas a un nivel superior. Ejemplo: la gente que pone en movimiento un objeto tiene intuitivamente en cuenta la resistencia que opone la gravedad a la aceleración y a la desaceleración. El cálculo matemático de las relaciones en juego habrá de representar luego un nivel de conocimiento superior al obtenido por la experiencia física. Otro ejemplo: poblaciones poco formadas por el espíritu técnico evalúan el tiempo empleado en atravesar un espacio determinado en función del esfuerzo físico por ellas realizado. Después, estas poblaciones aprenden a estimar el tiempo según los signos del tiempo objetivo, más abstracto.

De esta manera el sujeto se autoconstruye transformando sus estructuras de asimilación. El desarrollo de la razón es pues un proceso orientado que va del equilibrio en la asimilación, al desequi- librio y a la acomodación, produciendo un equilibrio cada vez más amplio. Pero, dice Piaget, lo propio de la vida mental no es alcanzar el equilibrio, sino crear sin cese nuevas relaciones y nuevos instrumentos de pensamiento (1975: 83). Si la línea del desarrollo es pues asintótica, una misma finalidad la orienta sin embargo constantemente: la de alcanzar una más grande operatividad racional. Ésta va a la par con una complejización de las estructuras. También las etapas del desarrollo están estrictamente determinadas, no por una meta a alcanzar, sino por la sucesión misma de los procesos: asimilación, desequilibrio y acomodación por abstracción reflexiva. Si he comprendido bien a Piaget, no es sino después que se puede hablar de finalidad en el desarrollo mental, cuando, por una suerte de abstracción reflexiva, uno sobrevuela la secuencia de los momentos sucesivos. Tendríamos así una teleología parecida a la que el Husserl de las Ideen señaló a propósito de la percepción.

Los límites de esta psicología del desarrollo son evidentes. Ella efectúa abstracción reflexiva sobre los contenidos de la razón y sobre la experiencia vivida con el fin de desprender de ahí la operatividad de las estructuras formales de la razón. Este centrarse en la razón operatoria y autoconstituida es evidentemente legítimo, si se tiene una pretensión sólo temáticamente limitada. Pero, en sus análisis de los pensamientos simbólicos que se apoyan en la 
analogía, Piaget conserva el referencial formal, haciendo de esto el criterio para juicios de valor. Las representaciones simbólicas y el lenguaje metafórico se encuentran así evidentemente desacreditados, y las finalidades humanas que ellos conllevan y expresan resultan sospechosas de ilusiones subjetivas.

En célebres investigaciones acerca de la actitud ética, L. Kohlberg ha trasladado el finalismo formal y racional de Piaget al desarrollo de la consciencia moral. Él distingue seis estadios que forman una secuencia rigurosamente determinada. Cada estadio sirve de apoyo al estadio siguiente superior ${ }^{2}$. El último, donde se supone que la consciencia es capaz de juzgar puramente según los principios morales formales, recuerda la filosofía ética de Kant. El método de Kohlberg es discutible, pues identifica prácticamente la consciencia moral con la solución de problemas éticos formalmente formulados como dilemas. Investigaciones con el método del propio Kohlberg han mostrado por lo demás que, a menudo, los estadios 5 y 6 se yuxtaponen a los estadios 3 y 4 .

2 Véase entre otros Lickona (1976: 31-53) y para una verificación crítica, Berling (1981). He aquí la secuencia de los estadios: 1) moral basada en la obediencia y el evitamiento de la punición; 2) egoísmo instrumental y reciprocidad egocéntrica; 3) juicio moral que toma como referencia la aprobación de los otros; 4) moral que adopta como normas el orden social y la autoridad; 5) moral que obedece a la ley concebida como contrato social; 6) juicio según los principios morales.
De todas maneras, así como la razón no es idéntica a su capacidad de operatividad formal, del mismo modo la consciencia moral comprende más de lo que de ella estudia la psicología cognitiva muy formal de Kohlberg.

La psicología del desarrollo ha sido seducida pues por la idea de progreso, heredada de las Luces, y tentada de demostrar que una finalidad opera en el centro de las experiencias y las búsquedas humanas, una finalidad que es aquélla de la razón en marcha hacia la racionalidad perfeccionada. La seguridad racional de esta psicología y su feliz confianza en el ser humano han contaminado algunas veces, incluso, a la psicología de la religión. Así J.W. Fowler (1981) ha pensado poder encontrar una secuencia de desarrollo análogo en el progreso de la creencia religiosa. Su mensaje bienaventurado ha sido durante algún tiempo la figura de revistas americanas de gran difusión. Investigaciones de verificación que he conducido hace algunos años demuestran mientras tanto que en el desarrollo religioso, de la infancia a la primera edad adulta, hay seis dimensiones esenciales, que su trayecto es muy desigual y que los desfases entre sus transformaciones causan numerosos conflictos, a veces de larga duración.

\section{El concepto de motivación}

"Motivación" es un término que en el siglo $\mathrm{XX}$ se ha derivado del verbo "motivar", cuyo sentido era: justificar 
la acción por las razones que uno tiene para realizarla. En psicología, el término filosófico de motivación ha tomado el sentido de la explicación de un comportamiento por tendencias psíquicas. La idea de un fin perseguido, presente en el sentido filosófico de aquel término -motivación-, no es más explícitamente connotada por el término psicológico. Sin embargo, acercándonos más, la idea de finalidad parece allí sobreentendida, imbricada en una estructura compleja de causalidades de naturaleza psicológica.

La intención, conforme lo hemos visto, es una finalidad inherente a la puesta en marcha de una acción y a su desarrollo. Al poner en perfil esta unidad, me he opuesto a la crítica que Von Wright ha hecho de la finalidad y que a menudo hace autoridad en la filosofía de la acción. Von Wright comienza por concebir la finalidad como un antecedente mental que precede la acción, y muestra a continuación que el dualismo que, según él, forma parte de la definición misma de la finalidad, vuelve ininteligible la acción. El análisis de la acción nos ha conducido a superar la fragmentación que hace en ella la crítica de Von Wright. Si la intención debe ser entonces concebida como animando y orientando la acción desde el interior, la cuestión que se plantea es la de saber cuál es la relación entre la intención y la motivación psicológica.

El término de motivación contiene la idea de fuerza motriz, ausente del tér- mino de intención. Éste designa la forma psíquica que hace actuar selectivamente. Esta palabra introduce pues la causalidad eficiente, atribuyéndole a ésta la naturaleza de un dinamismo orientado. Volvamos al ejemplo: "yo voy hacia la ventana para abrirla, a fin de ventilar el ambiente, porque me falta aire". La razón por la cual yo actúo se halla en el "porque" y en el "a fin de". Estos dos elementos forman un conjunto dinámico, pues, en la causa por la cual yo actúo (en el "porque"), la finalidad (el "a fin de") está ya implicada. La carencia que percibo (la falta de aire) es siempre carencia en un sistema referencial que la determina como carencia, y que le prescribe así una finalidad. Un ejemplo, de orden racional, para ilustrar el principio: si digo que cierto libro falta, en un determinado estante de mi biblioteca, es porque en virtud de mi sistema de clasificación éste debería estar allí. Al percibir que falta, inicio la acción para reponerlo. Esto vale tanto en el orden preconsciente o en el inconsciente como en los órdenes simbólicos racionales. La motivación psicológica es una fuerza orientada que hace experimentar la carencia como tal y que, de una manera psicológicamente espontánea, tiende a suplir ésta por medio de la acción.

Las motivaciones psicológicas pertenecen a las actividades espontáneas del cuerpo vivido teleonómico. Las acciones motivadas de éste son parte de nuestra personalidad, al punto que so- 
mos nosotros personalmente los que actuamos, incluso en los casos en los que no nos planteamos conscientemente la intención de perseguir una meta determinada. Así, cuando atravieso en forma más o menos distraída una calle, y adelanto un pie, si de pronto veo, oblicuamente, llegar una moto, lo retiro espontáneamente. El neurocientífico dirá que el cerebro ha puesto en marcha una estrategia compleja en orden al movimiento de atravesar la calle, incluso varios segundos antes de que yo tenga consciencia de decidirme a hacerlo. Él añadirá que la estrategia neuronal consiste también en adaptarse a las circunstancias locales y temporales. Pero no me parece legítimo pasar, sin más, de la estrategia adaptativa del sistema neuronal a la intuición de actuar personalmente, tal como lo testifica el lenguaje natural: "yo retiro mi pie". Un elemento particular y subjetivo interviene aquí: el momento afectivo del miedo que me concierne con respecto a la existencia de mi cuerpo. El miedo es una motivación: percibo un peligro y reacciono porque hay en mí la tendencia a mantener mi integridad corporal. Esta tendencia está presente en la percepción, en el gesto finalista -orientado a un fin-, y en la experiencia afectiva. Fuerza, percepción, finalidad y reacción afectiva forman un conjunto dinámico teleonómico.

En este conjunto, el dinamismo se despliega en la fuerza que es causa eficiente $\mathrm{y}$ en el objetivo determinado que, como causa final, ejerce su fuerza de atracción. El objetivo representado, conscientemente o no, actúa al interior de la acción, siendo el polo hacia el cual ella tiende. Por este círculo dinámico de la fuerza, de la motivación y de la finalidad, toda comprensión psicológica es indisociablemente explicación causal e interpretación, en referencia al fin perseguido, que determina el sentido de la acción. Así se dirá, por ejemplo, que la ambición impulsa a $\mathrm{X}$ a hacer esto a fin de obtener aquello. Y como la motivación en el sentido psicológico es en parte, o ampliamente, preconsciente (o inconsciente), y no coincide con la justificación consciente de las acciones, la explicación e interpretación de éstas son a menudo inciertas, exigen perspicacia, y se prestan a malentendidos. La observación psicológica nos enseña que son los momentos de crisis los que revelan con mayor claridad las motivaciones y finalidades de las cuales la misma persona no tiene una justa percepción. También los conflictos son, en este sentido, un objeto privilegiado de la investigación psicológica.

El concepto de motivación implica por tanto un cierto determinismo. No se puede, sin embargo, oponer simplemente libertad y determinismo, pues la explicación causal debe ser en todo caso completada con la idea de intención que le es solidaria. La solidaridad entre estos dos elementos representa precisamente el nivel psicológico de la 
estructura teleonómica. Allí actúa un ser viviente que está no sólo equipado para constituir con sus iniciativas su medio, sino también para afirmar su singularidad. La óptica determinista de la psicología no implica una filosofía determinista; y la psicología no sabría jamás sostener esta convicción. Pues la explicación-interpretación psicológica siempre da cuenta sólo de los factores que son necesarios para que el comportamiento sea tal como es, nunca lo suficiente como para comprenderlo totalmente. Nadie, ni el sujeto mismo, logra sacar a la luz la totalidad de los factores contextuales, positivos y negativos, que sobredeterminan la motivación y significación de sus comportamientos. El "azar" no es aquí sino el nombre de la ignorancia de lo que sería necesario para una explicación exhaustiva, desde luego en la hipótesis gratuita de un determinismo excluyente de toda libertad. Pero las lagunas irremediables en la explicación psicológica no justifican tampoco la afirmación de la libertad. Ésta no pertenece al orden de la observación psicológica.

En lo que concierne al concepto de motivación, es preciso todavía atraer la atención sobre la multiplicidad de las motivaciones, y sobre la imposibilidad de hacer un inventario de ellas, como algunos han soñado hacerlo. No se describen los rasgos de la "naturaleza humana" como se describe la naturaleza de las termitas o de las palomas. Se puede hablar de la tendencia a la con- servación de sí, o de la ambición, o de la necesidad de ser amado... Cada motivación se ramifica en diversas funciones y toma diferentes contenidos según los individuos y las sociedades.

No me detendré en las relaciones entre las motivaciones individuales $\mathrm{y}$ aquéllas de la sociedad a la que el individuo pertenece. Pienso que es legítimo hablar de tendencias y motivaciones propias a la sociedad, transponiendo así los conceptos de los procesos psicológicos al funcionamiento de las sociedades. Esta transferencia teórica se justifica tanto más que las representaciones; las intenciones y las fuerzas motrices de las acciones humanas son siempre por una parte sociales y por otra individuales. Las concepciones teóricas difieren sobre la prioridad a otorgar a estos aspectos y sobre la importancia de las interacciones.

\section{Freud}

La teoría psicoanalítica de Freud es particularmente interesante para nuestra problemática. Para Freud, su convicción general era que el ser humano no es libre; firme opinión que concordaba con su proyecto de elaborar una psicología científica en la que la interpretación era una explicación en la que se ponen en juego fuerzas y "mecanismos" adecuadamente regulados. Sin embargo, sus observaciones clínicas, hechas con precisión, y el rigor que ponía Freud en sus razonamientos explicativos, lo llevaron a precisar las corre- 
laciones entre causas y finalidades, y a poner en claro los límites de su poder explicativo. Me limitaré a señalar algunos datos que ilustran mi afirmación.

El esquema motivacional está presente en toda la teoría freudiana. Los comportamientos ponen en marcha las Triebe, palabra adecuadamente traducida como "pulsión". Por su empuje particular, estas pulsiones orientan al organismo psíquico hacia su satisfacción. Declarando vanos los proyectos de los psicólogos por elaborar un cuadro de ellas, Freud identifica sin embargo algunas: pulsión de agresión, de destrucción, de dominio, de autoconservación, de muerte, pulsión del yo, pulsión sexual. Estas pulsiones se encuentran implicadas en una historia personal que puede inhibirlas, negarlas o pervertir su trayecto. Freud está convencido de observar esto en los casos de sufrimientos afectivos y físicos no explicados por la fisiología ni por la neurología. Freud construye entonces su teoría explicativa de las neurosis al mismo tiempo que procede a terapias cuya técnica se justifica, según él, desde el punto de vista de la teoría y del diagnóstico. El término clave de la represión es ahora conocido universalmente como aquél que designa el proceso que produce los síntomas de las neurosis. Incluso si el noiniciado no ve en la palabra represión más que una metáfora sugestiva, esto basta para hacer comprender que la neurosis también es para Freud un hecho psíquico orientado a un fin, y no simplemente un hecho negativo, como lo sería una disminución psicológica consecutiva a una degeneración fisiológica. La neurosis es para Freud el efecto y la búsqueda de una reacción de salud del organismo psíquico. "Organismo psíquico" como la expresión por la cual él designa la totalidad compleja del individuo psíquico. Diferentes procesos ("mecanismos") integran este individuo, y colaboran en la vida psicológica sana como en la neurosis. Sin duda, se podría hablar también aquí de causas ascendentes y de causas descendentes. La causa descendente, responsable de la cooperación de los mecanismos, es aquí igualmente inaprensible. Se le infiere del hecho de que la neurosis representa un conjunto coherente. El término teleonomía se aplica perfectamente a estos hechos psicológicos.

Llevando tan lejos como es posible las interpretaciones-explicaciones, según el modelo de las actividades teleonómicas, Freud se vio obligado, a pesar de él, a señalar los límites de éste. Consideremos, a título de ejemplo, su "interpretación de los sueños". En su contenido psíquico, el sueño no es, tampoco, el producto de un simple déficit fisiológico y psicológico. Lo que es esencial en él, es el trabajo que realiza a fin de producir las sensaciones de satisfacción, incluso turbadas, de las representaciones del deseo pulsional (Triebwunschvorstellungen). Pero al producir estas satisfacciones por mecanismos teleonómicamente regulados, el sueño 
nos revela igualmente una característica fundamental del ser humano que hace que se manifieste el esquema teleonómico. Siendo psicológicamente una suerte de alucinación no patológica, el sueño pone en juego la búsqueda de placer en la representación de recuerdos de satisfacción. Dicho de otro modo, en el sueño se manifiesta un dato esencial del ser humano: el hecho de que en él el placer llega a ser una realidad autónoma ${ }^{3}$. Desde luego, este placer se apoya en recuerdos de experiencias que obedecen al esquema motivacional; pero el sentido del placer se muestra allí independiente. Este placer, que se muestra autónomo, no tiene más función al servicio del organismo vital regulado por la teleonomía. También el organismo psíquico del ser humano se halla disponible para comportamientos y maneras de ser contrarios a la vida, como en el caso de las perversiones, la anorexia, la depresión y la melancolía, la automutilación. El placer puede volverse en autodestrucción sin sentimiento de placer. Pero, la autonomía del pla-

3 Es preciso no confundir este hecho con "el principio del placer-displacer" que es el principio teleonómico fundamental en el sistema freudiano. Este principio ordena las relaciones de asimilación-interiorización y las de rechazo que caracterizan los intercambios entre el individuo y su medio. La experiencia del placer se eleva sobre este principio teleonómico y representa ya una interioridad psicológica en la que el principio juega de nuevas y múltiples maneras. cer viene a ser también el lugar de las creaciones culturales por la sublimación de la libido.

La observación de psicopatologías y la consideración del desarrollo psicológico, en todo lo referido a la sexualidad, llevan también a Freud a concluir en la tesis de la excepción humana en el orden de lo viviente, este orden que, como hemos visto, Husserl designaba como la animalische Natur en el ser humano. En el ser humano -dice Freudla sexualidad no es más un instinto programado cuya finalidad está determinada. Freud decide asimismo reservar a la sexualidad humana el término Trieb, y a la del animal el de instinto. La clínica, que ha conducido a Freud de la neurología a la psicopatología, le impone así el problema central de un organismo psíquico compuesto por dinamismos teleonómicos, pero también fundamentalmente alterado y desestabilizado por la libido que, siendo erótica, no tiene finalidad predeterminada, luego tampoco un desarrollo naturalmente regulado. Esta ausencia de finalidad tiene su contraparte en la capacidad de placer que se independiza también de la órbita de las funciones vitales y motivantes de donde nació. A estas particularidades humanas se añade la excepcional premaduración biológica del ser humano en ciernes, experimentada como angustia, y que las motivaciones vitales-psicológicas la hacen desarrollarse en apegos libidinosos a las figuras parentales. 
Antropólogos como A. Gehlen y Leroy-Gourhan han planteado igualmente el problema de la particularidad del ser humano en el reino de los vivientes. Tomando el punto de vista del viviente, apreciado en el círculo dinámico individuo y medio, ellos observan una carencia constitutiva en la adaptación del ser humano a éste. La palabra "adaptación" designa, precisamente, el circuito cerrado del ser viviente que crea su medio de vida, en tanto el medio se presta a las actividades que él debe ejercer para sobrevivir y hacer sobrevivir a su especie. La ausencia de semejante adaptación natural empuja al ser humano, dicen los antropólogos, a suplir esta carencia con la creación de artefactos y del mundo simbólico de los signos. Los antropólogos no comparten pues la manera de pensar de un cierto número de psicólogos que, aparentemente fascinados por el círculo del viviente y de su nicho ecológico, conciben de preferencia los comportamientos humanos en términos de necesidad y adaptación.

$\mathrm{Al}$ señalar la ruptura del ser humano con el círculo teleonómico del viviente y del medio, los antropólogos están cerca de Freud. Los pasos de unos y otro son, sin embargo, en cierto modo, opuestos. El antropólogo adopta una visión de sobrevuelo sobre el reino de lo viviente, en tanto que Freud pone su punto de partida en el individuo distendido en su interior por dinamismos y orientaciones que, respaldándose en los dinamismos teleonómicos, se les esca- pan y, desarreglando éstos algunas veces seriamente, llegan al punto de producir enfermedades y sufrimientos de un orden muy particular, como es el orden psicológico. Este orden no es, simplemente, ni el del cuerpo ni el de la razón, en tanto que sistema dinámico regulado por las leyes de la lógica. El orden psicológico depende del cuerpo viviente y de la razón, pero él repercute también sobre estos dos órdenes, al punto de poder perturbar su funcionamiento.

Es imposible presentar aquí la elaboración extremadamente compleja de las concepciones freudianas acerca de las finalidades en la psicología del ser humano. No puedo más que evocar algunos elementos. El más importante, sin duda alguna, la tesis de que la ausencia de preprogramación sexual y la presencia del placer autónomo hacen nacer al sujeto yoico, por una reflexión de la experiencia misma del cuerpo erótico; reflexión que se puede comparar a la reflexión noética cartesiana que hace nacer el yo como consciencia de sí mismo. El yo, así constituido, tendrá la posibilidad y la tarea de darse a sí mismo las finalidades que la naturaleza teleonómica no le prescribe. Estas finalidades le son propuestas por los "valores culturales". El lenguaje que transmite estos valores los vuelve presentes al interior del deseo, en el "ideal del yo", como la causa interna en donde se origina el movimiento hacia estos valores como objetos del deseo humano. En 
términos de finalismo se puede decir que la ausencia de preprogramación de la libido le otorga, mientras tanto, la posibilidad y la necesidad de autoprogramación. Necesidad tanto como posibilidad, pues, según la tesis de Freud, las obras de la sublimación cultural de la sexualidad son indispensables para la resolución de los conflictos psicológicos que acarrea la ruptura antropológica con la teleonomía del viviente.

La ruptura antropológica que se produce en el ser humano nos conduce a concebir muchas actividades humanas como estando por una parte metamotivadas; dicho de otro modo: transcendiendo la explicación psicológica. Sobre este punto esencial, Freud se halla, regularmente, en contradicción consigo mismo al tratar de reducir las creaciones culturales a funciones psicológicas ocultas.

Los principios teóricos de Freud contienen las directivas esenciales para la terapia específicamente analítica. Ésta consiste en la curación que el enfermo se hace a sí mismo, por medio de sus palabras dichas en libertad de asociación, en el dispositivo adecuado a esta palabra. Este estilo de palabra se justifica por los dos grandes principios teóricos de Freud. El primer principio consiste en reconocer en el psiquismo las finalidades limitadas y de naturaleza teleonómica. Estas finalidades rigen la historia psicológica del sujeto, su neurosis y su palabra en el dispositivo terapéutico. Para aclarar esto se preci- saría, evidentemente, analizar en detalle los diferentes elementos que evoca mi proposición. El segundo principio, el de la ruptura con las leyes teleonómicas, impone al terapeuta psicoanalista la neutralidad filosófica, religiosa y ética en sus intervenciones terapéuticas. Puesto que no hay finalidad psicológica englobante, y que lo propio del ser humano es el darse a sí mismo las finalidades que construyen el sentido de su existencia, el terapeuta no está autorizado sino a restituir al enfermo, tan plenamente como sea posible, el poder y la libertad psicológica para cumplir su tarea. No hay "pulsión de perfeccionamiento de sî”, afirma Freud contra Jung. La ética del terapeuta analista le impone respetar la libertad de su paciente y limitarse a la interpretación de lo que se halla inconsciente en su palabra dicha en libertad de asociación.

\section{NOTA SOBRE JUNG}

Se sabe que Jung se rebeló contra Freud, esencialmente, porque él no aceptó la reducción que hizo éste de los símbolos a representaciones reprimidas de los deseos sexuales. Jung quería restaurar la dimensión espiritual y religiosa del psiquismo. Pero es sorprendente observar que en realidad él naturaliza estas dimensiones; precisamente, porque quiso mostrar que ellas son finalidades psicológicamente naturales. Para Jung, en efecto, los símbolos que despliegan las ideas religiosas y que ponen en acto los ritos, son emanaciones de 
las formas arquetípicas inscritas en la naturaleza del psiquismo humano. Como los genes se expresan en la formación del cuerpo, así los arquetipos jungianos se expresan en la formación cultural de los símbolos. De este modo, la finalidad de los símbolos es la de mantener al viviente psíquico en equilibrio, por la expresión misma de lo que integra la naturaleza de su psiquismo. Dicho de otro modo, la finalidad de la expresión simbólica es la de una entelequia que forma parte del círculo teleonómico. Es este espiritualismo naturalista el que le permite a Jung absorber todas las religiones, todas las filosofías y todos los delirios en un universo gnóstico y alquimista en expansión. La mixtura jungiana, de un espiritualismo esotérico y de una psicología de aspecto científico, atrae al parecer a incrédulos nostálgicos de imaginación religiosa; y algunos teólogos buscan una alianza, sin mayor esfuerzo, del cristianismo con las ciencias humanas. Esto me parece manifiesto en el éxito de Drewermann, quien proclamándose en todo desde el psicoanálisis, se adhiere en realidad a la corriente jungiana.

\section{CONCLuSIón}

El esquema dinámico constitutivo de las actividades psíquicas representa un círculo teleonómico. Este dinamismo teleológico no requiere de la consciencia libre que plantea sus propios fines. También se le encuentra en los automa- tismos que facilitan nuestra existencia normal. Freud nos ha mostrado que él se halla igualmente en actividad en el acto englobante e inconsciente de la represión, así como en el trabajo regulado por el cual el psiquismo constituye los síntomas de las neurosis. Precisamente, los casos clínicos nos revelan que antes de toda consciencia explícita, el psiquismo humano está señalado por rupturas del círculo teleonómico. Rupturas que hacen que el ser humano, por no estar más vitalmente programado por la libido, pueda y deba autoprogramarse, bajo pena de autodestruirse como ego. Esta posibilidad ocurre con el advenimiento del yo. A partir de allí la motivación llega a ser, por una parte, auto-motivación de un ser humano que se da su propia finalidad.

El yo mismo es el producto de una autoconstitución del individuo en tanto que él es un cuerpo psíquico ya autocentrado en la experiencia del placer y del displacer. Esta autoconstitución se hace en respuesta a las relaciones humanas en las cuales él es recibido. Estas relaciones son formadas por valores culturales, y ellas a su vez transmiten estos valores, implícita y explícitamente. En su autoprogramación el yo las asume y las descarta de modos variables; pero, ninguna finalidad psicológica natural sabría dar explicación de estas historias personales. Entre los valores culturales, el yo encuentra la finalidad formalmente lógica que lleva en sí mismo el lenguaje como una de sus po- 
sibilidades. La psicología del desarrollo de Piaget se ha concentrado sobre esta finalidad. Uno no se sorprende que ésta presente una especie de teleonomía, puesto que la ley (el nomos) de la lógica la gobierna.

La finalidad del psiquismo se libera parcialmente del círculo teleonómico. Respaldándose en éste, el ser viviente que es el ser humano puede lograr la realización de su humanidad por medio de acciones en las que la gratuidad se impone sobre la motivación, la creatividad deja tras de sí sus apoyos finalistas, y el goce no es más la búsqueda de placer. En el límite extremo, asintótico: en el que el amor es sin "porque" y sin "por qué". Pero este límite es la referencia al Dios bíblico.

\section{REFERENCIAS}

Bergling, K. (1981). Moral development. The validity of Kohlberg's theory. Stockholm: Almqvist et Wiksel.

Bernet, R. (1994). La vie du sujet. Recherche sur l'interprétation de Husserl dans la phénoménologie. Paris: PUF.

Fowler, J.W. (1981). Stages of faith: The psychology of human development and the quest for meaning. San Francisco: Harper \& Row.

Husserl, E. (1963). Recherches logiques. Paris: PUF.

Karli, P. (1995). Le cerveau et la liberté. Paris: Odile Jacob.

Lickona, T. (Ed.). (1976). Moral stages and moralization. The cognitive development approach. New York: Holt, Rinehart et Winston.

Monod, J. (1970). Le hasard et la nécessité. Paris: Gallimard.

Piaget, J. (1975). L'Équilibration des structures cognitives. Paris: PUF.

Vergote, A. (1993). Nature et culture. Revue d'étique et de théologie morale.

Wittgenstein, L. (1969). Philosophische Untersuchungen. Frankfurt: Suhrkamp. 